\title{
Improving forecasts of El Niño diversity: a nonlinear forcing singular vector approach
}

\author{
Lingjiang Tao ${ }^{1,2} \cdot$ Wansuo Duan $^{1,2} \cdot$ Stephane Vannitsem ${ }^{3}$
}

Received: 16 December 2019 / Accepted: 9 May 2020 / Published online: 20 May 2020

(c) The Author(s) 2020

\begin{abstract}
Observations indicate that two types of El Niño events exist: one is the EP-El Niño with a warming center in the eastern tropical Pacific, and the other is the CP-El Niño with large positive SST anomalies in the central tropical Pacific. Most current numerical models are not able to accurately identify the different types of El Niño. The present study examines the dynamic properties of the ENSO forecast system NFSV-ICM which combines an intermediate-complexity ENSO model (ICM) with a nonlinear forcing singular vector (NFSV)-based tendency perturbation forecast model. This system is able to distinguish the different types of El Niño in predictions. Hindcasts show that the NFSV-ICM system is able to capture the horizontal distribution of the SST anomalies and their amplitudes in the mature phase of not only EP-El Niño events but also CP-El Niño events. The NFSV-ICM is also able to describe the evolution of SST anomalies associated with the two types of El Niño up to at least two-season lead times, while the corresponding forecasts with the ICM are limited to, at most, one-season lead times. These improvements are associated with the modifications of the atmospheric and ocean processes described by the ICM through the NFSV-based tendency perturbations. In particular, the thermocline and zonal advection feedback are strongly modified, and the conditions of the emergence of both EP- and CP-El Niño events are improved. The NFSV-ICM therefore provides a useful platform for studying ENSO dynamics and predictability associated with El Niño diversities.
\end{abstract}

\section{Introduction}

The prediction and its predictability of ENSO have been studied for decades since the first coupled ENSO model was developed (Zebiak and Cane 1987). To date, more than twenty models have been used to routinely predict the airsea state of the tropical Pacific Ocean (see https://iri.colum bia.edu/our-expertise/climate/forecasts/enso/current/). These models range from intermediate-complexity models (ICMs) to fully coupled models and, on average, have a suitable forecast accuracy with a 6-month lead time; it is very difficult to rank the models overall in terms of both complexity

Wansuo Duan

duanws@lasg.iap.ac.cn

1 State Key Laboratory of Numerical Modeling for Atmospheric Sciences and Geophysical Fluid Dynamics, Institute of Atmospheric Physics, Chinese Academy of Sciences, 100029 Beijing, China

2 University of Chinese Academy of Sciences, 100049 Beijing, China

3 Royal Meteorological Institute of Belgium, 1180 Brussels, Belgium and forecast skill. Nevertheless, it is also clear that almost all models are hardly able or unable to identify the observed El Niño types, i.e., the eastern Pacific El Niño (EP-El Niño) and central Pacific El Niño (CP-El Niño) (Ashok et al. 2007; Yang and Jiang 2014; Zheng and Yu 2017; Ren et al. 2018b). The former has a warm SST centered in the eastern Pacific and the latter shows a warm SST centered in the central Pacific near the dateline. These two types of El Niño events have different climate effects, and it is important to identify them in ENSO predictions (Ashok et al. 2007; Lee et al. 2018). Hendon et al. (2009) used an ENSO model from the Australian Bureau of Meteorology and found that the model skills deteriorated in distinguishing El Niño patterns after one-season lead time. Jeong et al. (2012) investigated the performance of a multi-model ensemble seasonal forecast system from the Asia-Pacific Economic Cooperation (APEC) Climate Center and showed that the model can discern the main difference between EP-and CP-El Niño events less than four months ahead. Even Ren et al. (2018a) emphasized that the mature phase of EP- and CP-El Niño events can only be identified in some models at a one-month lead time. It is clear that the prediction towards El Niño diversities is a substantial challenges. 
To increase the ENSO prediction skills, one alternative method is to improve the initial conditions by adding observations and applying an advanced assimilation scheme. The "spring predictability barrier" (SPB) - the common phenomenon in which prediction skills usually decline rapidly when the predictions bestride spring - is known to be mainly related to the presence of initial errors (Moore and Kleeman 1996; Zhang et al. 2005; Yu et al. 2009; Jin et al. 2008; Duan and $\mathrm{Hu}$ 2016; Tao et al. 2017). Therefore, reducing initial errors can weaken the SPB phenomenon and improve the ENSO prediction skill (Duan and Wei 2013; Tao and Duan 2019; Hu and Duan 2016; Tao et al. 2018). Tian and Duan (2016) explored the predictability of two types of El Niño within a perfect model scenario and demonstrated that initial errors can cause a less significant error growth during CP-El Niño prediction than during EP-El Niño prediction as well as for the SPB, which indicates that the CP-El Niño prediction tends to be more predictable than the EP-El Niño in the absence of model errors. Ren et al. (2016) also show similar findings. However, in realistic forecasts, EP-El Niño displays better predictibility than CP-El Niño. It is therefore expected that model errors are the main limiting factors on predictions of CP-El Niño, and therefore on predictions of El Niño diversities. The identification to the distinct impacts of model errors on the prediction of the development of $\mathrm{El}$ Niño events with various patterns is therefore a key to the improvement in their prediction skills.

Current climate models face several important difficulties in simulating El Niño diversity. Yu and Kim (2010) evaluated the performance of models from the World Climate Research Programme's Coupled Model Intercomparison Project Phase 3 (CMIP3) and reported that most CMIP3 models can only simulate a single type of El Niño event (Ham and Kug 2012). Even with the CMIP5, although some models can describe El Niño diversity, the model biases are still notable, e.g., the simulated interannual variability in the SST is shifted far more westward than the observations in the tropical Pacific (Kug et al. 2010; Choi et al. 2011; Capotondi 2013). As a result, the modeled CP-El Niño events are unrealistic and centered far more to the west than the observations; this modeling error has been found to be driven by the unrealistically strong trade winds (Taschetto et al. 2014). In addition, Kim et al. (2012) demonstrated that the extratropical forcing to the central Pacific SST is relatively weaker than that observed, thus causing the amplitude of the simulated CP-El Niño to be weaker than that observed.

Since model uncertainties are the main factor that strongly influences the El Niño diversity prediction, it is necessary to improve the model to reduce the impact of the model error on El Niño diversity prediction. However, the potential sources of model errors are broad (e.g., the uncertainties occurring in model parameters, parameterizations, physical processes, etc.) and their respective impacts are hardly distinguishable (e.g., Vannitsem and Toth 2002; Barkmeijer et al. 2003; Nicolis et al. 2009). Thus, some studies only focus on the model output and introduce many methods to correct the model results, such as model output statistics (MOS) correction (Ji et al. 1996) and the state-dependent correction (Chen et al. 2000). Recently, Duan et al. (2014) contributed model errors with various sources to the model tendency and proposed the idea of using nonlinear forcing singular vector (NFSV) approach (Duan and Zhou 2013) as a tool to incorporate the impact of model errors on the tendency perturbation of the SST equation. With such NFSVbased tendency perturbations, they successfully reproduced the El Niño diversities using the Zebiak-Cane model (Zebiak and Cane 1987) as well as the relevant air-sea states. Tao and Duan (2019) further referred to such approach as the NFSV-assimilation approach, in which the observations are assimilated and the tendency equation is optimized to ensure that the simulation is as close as possible to the observation. This approach does not consider the details of model error sources but macroscopically considers the combined effect of all kinds of model errors. This effectively simplifies the overall problem. Based further on the NFSV-assimilation approach, Tao and Duan (2019) developed a model error forecast model (i.e., the NFSV-based tendency perturbation forecast model), which is embedded into an ICM developed by Zhang et al. (2003) to formulate a new ENSO forecast system (referred to as NFSV-ICM). They found that the NFSV-ICM made much better predictions of the Nino3.4 index associated with ENSO than the ICM. In particular, the NFSV-ICM has a much higher skill in predicting the SST anomaly in the central tropical Pacific than that in the eastern tropical Pacific. This naturally raises the question on the ability of the NFSV-ICM system to distinguish the type of El Niño during forecasts. Despite the fact that Tao and Duan (2019) already realized this point, they did not explore in detail to what extent the NFSV-ICM can predict/identify the types of El Niño. More specifically, they did not investigate how the NFSV-ICM improves the prediction skill on different ENSO types in terms of their dynamics and physics. Undoubtedly, addressing this question will allow for a better understanding of the occurrence of El Niño diversities and improve the forecast skill of different types of ENSO.

The remainder of the paper is organized as follows. In Sect. 2, the NFSV-ICM and related observations are described, and in Sect. 3 the prediction skills of the NFSVICM for two types of El Niño events are evaluated. To address why the NFSV-ICM provides superior model performance in identifying different types of El Niño in predictions, Sect. 4 analyzes the dynamics and physics of the NFSV-based tendency perturbation in correcting bias in predicting the two types of El Niño events. Finally, a summary and a discussion are provided in Sect. 5 . 


\section{NFSV-ICM and observations}

The NFSV-ICM includes two components. One component is the ICM ENSO model, which was developed by Zhang et al. (2003). This model is a air-sea coupled model covering the tropical Pacific that includes a wind stress model, a dynamic ocean model and a nonlinear SST model; the other component is the model perturbation forecast model derived via the NFSV-assimilation approach. Since the ICM captures the main dynamics of ENSO evolution, such as the largescale air-sea coupling and the thermocline effect on SST, it properly simulates the interannual variability of the tropical Pacific (Zhang et al. 2005; Gao and Zhang 2017; Zhang and Gao 2017; Mu et al. 2019), together with useful skill for ENSO predictions (Zhang and Gao 2016a). Note that there are still large uncertainties in the ENSO predictions, especially for the different types of El Niño; many efforts have been made to reduce the uncertainties in this model (Zheng and Zhu 2016; Gao and Zhng 2017; Goa et al. 2018; Zhang et al. 2018). In contrast to previous correction methods, in the NFSV-ICM, the NFSV-based tendency perturbation forecast model is constructed to deal with the model errors.

The NFSV-based tendency perturbation forecast model is derived by applying the NFSV-assimilation approach to the historical simulation of realistic ENSO events made by the ICM. Let us assume that the ICM can be written as $\boldsymbol{x}=\boldsymbol{G}(x, t)$; then, the NFSV-ICM is

$\boldsymbol{x}=\boldsymbol{G}(x, t)+\mathbf{f}_{t}$,

where $\mathbf{f}_{t}$ is determined by minimizing

$J(\mathbf{f})=\sum_{t}(\mathbf{H} x(\mathbf{f}, t)-\boldsymbol{y}(t))^{\mathrm{T}} \mathbf{R}^{-1}(\mathbf{H} \boldsymbol{x}(\mathbf{f}, t)-\boldsymbol{y}(t))$,

where $y(t)$ represents the observation, $\mathbf{H}$ and $\mathbf{R}$ are the observation operator and observation error covariance, respectively, and $\boldsymbol{x}(\mathbf{f}, t)$ is the solution to Eq. (1). After NFSVassimilation, the optimized forcing vector $f^{*}$ describes the perturbation that offsets the combined impacts of model errors from various sources. More specifically, for the ICM, the forcing vector $\mathbf{f}$ is set to be added to the tendency equation of the SST model to make the SST simulation $\boldsymbol{x}\left(\mathbf{f}^{*}, t\right)$ closest to the observations $\boldsymbol{y}(t)$. In addition, $\mathbf{f}$ is constant within one month since a high frequency of $\mathbf{f}$ may destroy the adjustment in the air-sea coupling (Duan et al. 2014). For example, when the 1-year observations are assimilated using the NFSV-based assimilation (Eq. 2), we can obtain 12 corresponding NFSV-based perturbations. Then, by assimilating the historical observed monthly SST during the period from 1960 to 1996 , a set of corresponding monthly NFSV-based tendency perturbations can be obtained during 1960-1996 [in total, 37× 12 NFSV-based tendency perturbations; details are provided in Tao and Duan (2019)].
During the prediction period, only the initial observation can be obtained; therefore the corresponding NFSV-based tendency perturbations that depend on the observations during the prediction period are not accessible. Nevertheless, the NFSV-based tendency perturbations depend on the initial states of observed events and can therefore be estimated in advance. Tao and Duan (2019) constructed the NFSV-based tendency perturbation forecast model by using a singular vector decomposition (SVD) approach, which builds the statistical relationship between the NFSV-based tendency perturbation and the SST field. The NFSV-ICM is thus obtained by embedding the NFSV-based tendency perturbation forecast model into the ICM.

Reanalysis data sets of the SST and wind stress are used in the present work to evaluate the forecast quality of the NFSV-ICM. The SST data are derived from the Extended Reconstructed SSTv3b of the National Oceanic and Atmospheric Administration (NOAA) (Smith et al. 2008), and the wind stress data are obtained from the reanalysis data of the National Centers for Environmental Prediction-National Center for Atmospheric Research (NCEP/NCAR, Kalnay et al. 1996).

\section{Hindcast experiments using the NFSV-ICM}

As mentioned in Tao and Duan (2019), the NFSV-ICM outperforms the ICM in predicting the Nino3.4 index associated with ENSO. In this section, we will further study its skills in identifying the different types of El Niño events in predictions. Note that there are quite a few approaches to defining the types of El Niño events (Ashok et al. 2007; Kao and Yu 2009; Kug et al. 2009; Ren and Jin 2011); as a result, there exist differences in the El Niño group members associated with the EP- and CP-El Niño events in observations. To avoid this inconvenience, we determined the types of $\mathrm{El}$ Niño events based on a consensus result derived from the different approaches, similar to the work of Zheng and $\mathrm{Yu}$ (2017). Hence, there are a total of eight EP-El Niño events and ten CP-El Niño events identified from the SST data from 1960-2016 (see Table 1).

\subsection{Niño3.4 index}

The hindcast experiments were performed with 1-, 2-, 3-, $\ldots$, and 12-month lead times from the first day of each calendar month during the period of 1960-2016 for both the ICM and NFSV-ICM. The anomaly correlations and root mean square errors (RMSEs) between the observed and predicted Niño3.4 index are calculated in terms of the CP-El Niño or EP-El Niño period, as shown in Fig. 1. The NFSV-ICM has better skills than the ICM in predicting SST anomalies, with the former presenting lower RMSEs 
Table 1 The observed EPand CP-El Niño events from 1960-2016

\begin{tabular}{llc}
\hline El Niño type & Year & $\begin{array}{c}\text { Number } \\
\text { of events }\end{array}$ \\
\hline EP-El Niño & 1969/70, 1972/73, 1976/77, 1982/83, 1986/87, 1997/98, 2006/07, 2015/16 & 8 \\
CP-El Niño & $\begin{array}{l}\text { 1963/64, 1965/66, 1968/69, 1977/78, 1987/88, 1991/92, 1994/95, 2002/03, } \\
\\
\end{array}$ & 10 \\
\hline
\end{tabular}

(a)

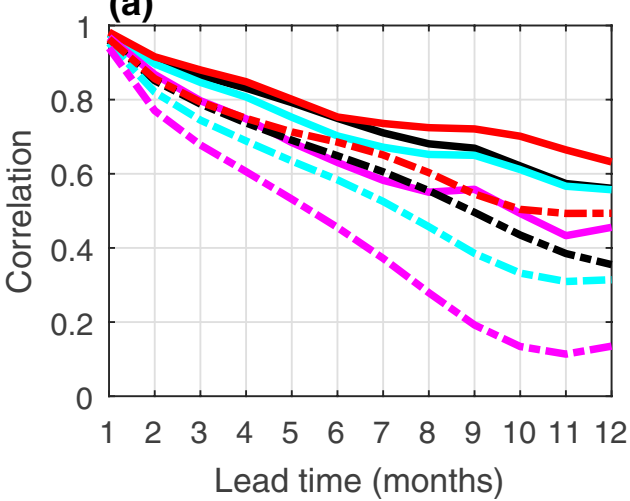

(b)

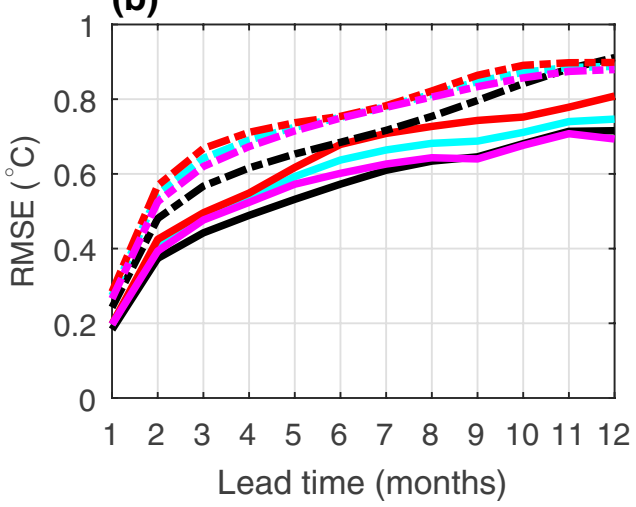

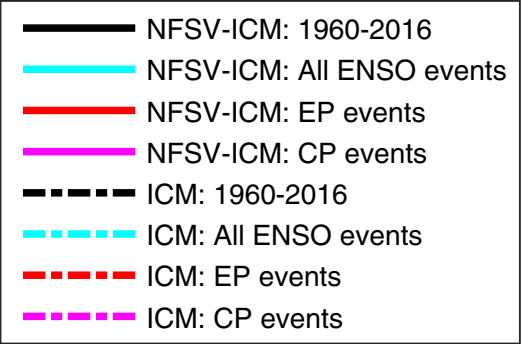

Fig. 1 a Anomaly correlations and $\mathbf{b}$ RMSEs between the observed and predicted SST anomalies in the Niño3.4 area as a function of lead times. Hindcasting was conducted for the SST anomalies in the period from 1960 to 2016 . The results derived from the NFSV-ICM (solid curves) and ICM (dashed curves) are shown separately for the different ENSO events. The black curves are prediction skills for the Niño3.4 index from 1960 to 2016, the blue curves are for all El Niño event-related SST anomalies, and the red and pink curves are for the EP- and CP-El Niño event-related SST anomalies, respectively can be increased from 4 months using the ICM to 7 months using the NFSV-ICM.

Although the prediction accuracy of the NFSV-ICM for the Niño3.4 index is significantly improved compared with that of the ICM, the source of its high ENSO prediction abilities is worth investigating. To address this issue, we now focus on examining the horizontal distributions and evolutions of SST anomalies during EP- and CP-El Niño events in the following sections.

\subsection{Mature phases of EP- and CP-El Niño events}

Figure 2 shows the composite SST anomalies for the observed and predicted CP-El Niño events in winter (November-December-January, i.e., the mature phase). Both the ICM and NFSV-ICM are able to identify the main features of the CP-El Niño events with warming centers in the central tropical Pacific with short lead times. However, with increasing lead times, the SST anomalies predicted 
(a) Obs.

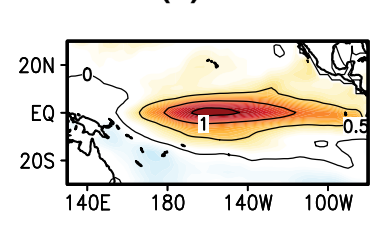

(b) ICM
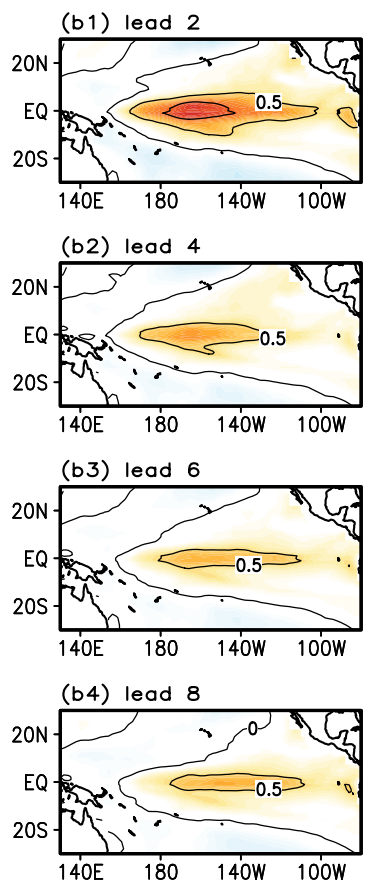

(c) NFSV-ICM
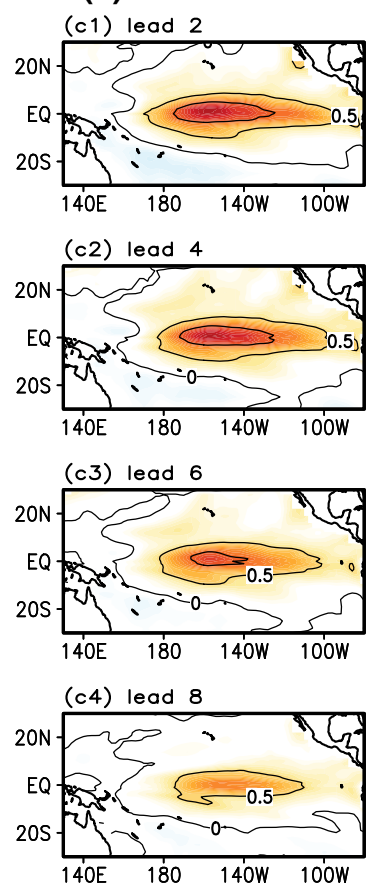

(d) Diff.
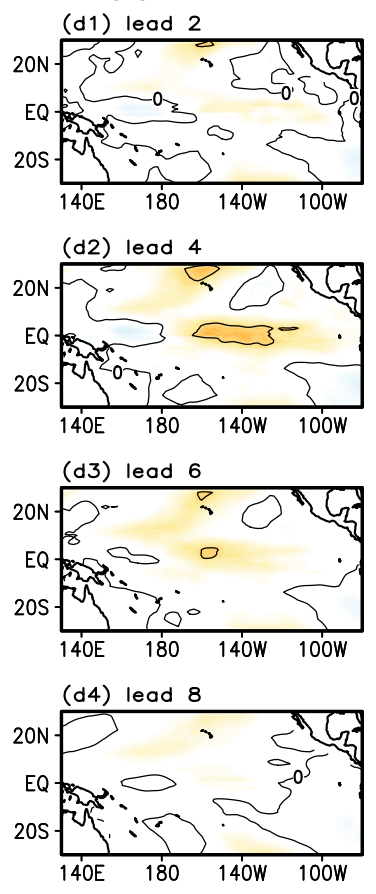

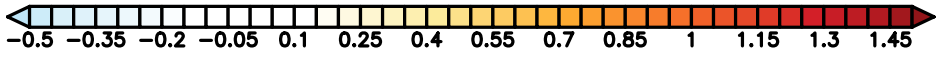

Fig. 2 Composite SST anomalies for the mature phase (NovemberDecember-January) of the CP-El Niño events derived from the a observations, predictions by $\mathbf{b}$ the ICM and $\mathbf{c}$ the NFSV-ICM, as well

by the ICM tend to be weaker, and the warm center is displaced eastward. As a result, the ICM may generate a false positive prediction for a weak EP-El Niño event or a normal year when initialized in the early year. In contrast, the NFSV-ICM is able to predict a realistic central tropical Pacific warming event at a long lead time when the tropical Pacific experiences the CP-El Niño event. The major differences between the SST anomalies predicted by the ICM and NFSV-ICM occur in the central equatorial Pacific (see Fig. 2d), especially with a 4-month lead time. To visualize their CP-El Niño prediction skills in detail, some forecasts at 4-month lead times for CP-El Niño events are plotted individually in Fig. 3. It can be seen that the ICM tends to lose its skill in CP-El Niño predictions beyond a one-season lead time and is likely to predict a CP-El Niño into a La Niña year or a normal year. Although there exist CP-El Niño events that are captured in the ICM predictions (e.g., the 1991-1992 CP-El Niño), their intensities are usually underestimated. When using the NFSV-ICM, the predicted SST anomalies are quite close to those in the observations in terms of both the warming center and the amplitude (Fig. 3c), and the spatial correlation coefficients between the observed SST anomalies and their predictions can be higher than 0.7 , even approaching to 1 for the 4-month lead time predictions. as $\mathbf{d}$ the differences between the NFSV-ICM and ICM. From top to bottom, the predictions are generated at 2-, 4-, 6- and 8-month lead times. The contour interval is $0.5^{\circ} \mathrm{C}$

Composites of the observed EP-El Niño events are displayed in Fig. 4, as well as the corresponding predictions using the NFSV-ICM and ICM. Comparing Figs. 2 and 4, it can be seen that the prediction accuracy for the horizontal distribution of the SST anomalies for EP-El Niño events is often higher than for the horizontal distribution of the SST anomalies for CP-El Niño events. Both the ICM and NFSV-ICM predictions present a relatively realistic warming center position for EP-El Niño events, but the former tends to predict a weaker-than-observed El Niño event as lead time increases. Although the improvement in the prediction of the EP-El Niño-related SST anomalies is not as significant as that for the CP-El Niño along the equator (see Fig. 4d), substantial differences between the NFSV-ICM and ICM predictions are presented off the equator. The ICM prediction tends to produce a much cooler ocean state off the equator while the NFSV-ICM reduces such cold bias and yields much better large-scale SST anomalies in the whole tropical Pacific.

In addition, by evaluating the prediction results in Figs. 2 and 4 , it is clear that the main differences between the two types of El Niño are discernable by both the ICM and NFSVICM at short lead times. However, beyond a 4-month lead time, the ICM predictions only show similar patterns for both EP- or CP-El Niño events, with a warming center in 
(a) Observation
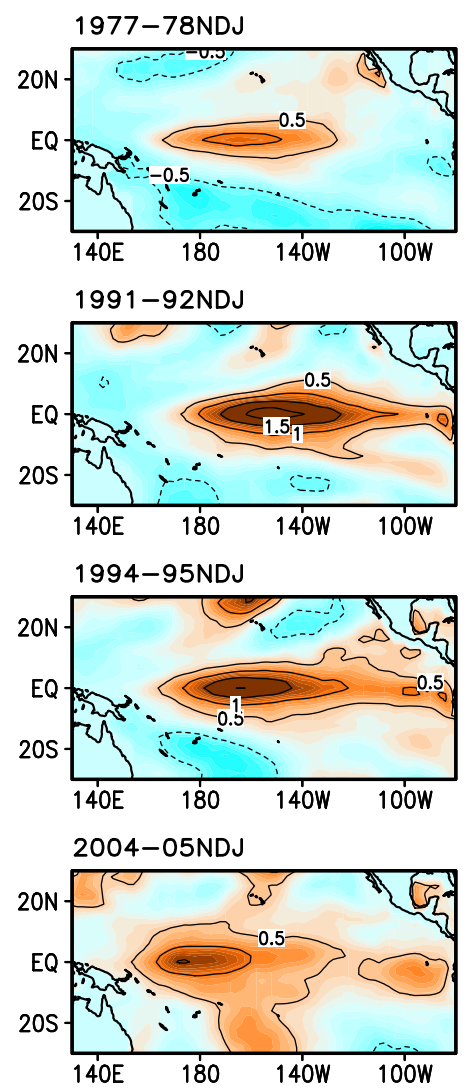

(b) ICM
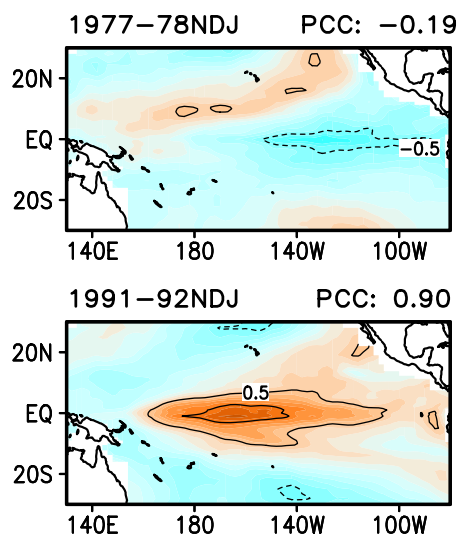

1994-95NDJ PCC: -0.37
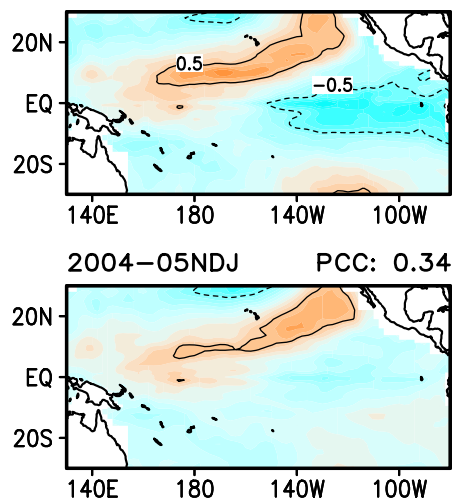

(c) NFSV-ICM
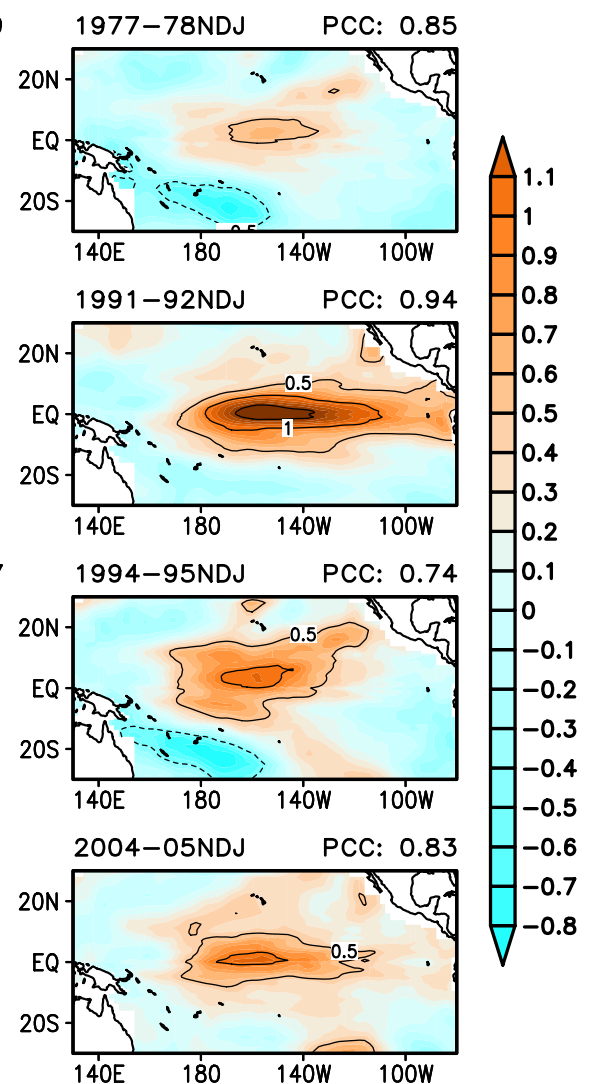

Fig. 3 The winter SST patterns of CP-El Niño in the a observations, b ICM predictions and c NFSV-ICM predictions, where the lead time is four months. PCC is the pattern correlation coefficient between the observation and prediction. The contour interval is $0.5{ }^{\circ} \mathrm{C}$

the central and eastern Pacific. Using the NFSV-ICM, the predicted CP-El Niño event still features a warming ocean in the central tropical Pacific at long lead times and the predicted EP-El Niño event shows a large warming area in the eastern Pacific.

\subsection{Evolution of EP- and CP-EI Niño events}

Not only are the SST anomalies regarding the two types of El Niño events in the mature phase improved using the NFSV-ICM but their evolutions and corresponding atmospheric states are also improved. Figure 5 shows the evolution of the observed CP-El Niño as well as the hindcasts with a 4-month lead time by the ICM and NFSV-ICM. In the observations, there exist two ways to produce the SST anomalies in the central tropical Pacific. One way is related to the initial warming near the dateline that has been documented to be generated from anomalous warming in the northern equatorial countercurrent (Zhang and Gao 2016b). Such weak warming gradually develops due to the triggered westerlies in the western Pacific in turn driving the warm water eastward. The other way is related to the westerly anomaly in the subtropical Pacific. As the trade wind weakens, the surface heat flux is reduced causing a positive heat flux into the ocean. A meridional SST dipole mode coupled with the local westerly wind, known as the Pacific meridional mode (PMM) (Chiang and Vimont 2004), then develops in April (0). This mode is sustained and gradually amplified through wind-evaporation-SST (WES) feedback (Xie and Philander 1994). In addition, winds converge in the central tropical Pacific, which further enhances the SST anomalies. However, in the hindcast experiments, both the ICM and NFSV-ICM failed to capture the westerly anomaly in the subtropical Pacific. This implies that the effect of PMM on the central Pacific is hardly captured with the models. As a result, the predicted SST anomalies are smaller than those observed in July (0); nevertheless, the ICM predictions are worse, and the related warming signal almost disappears in July (0). In addition, during the decay phase of the CP-El Niño event, the ICM predictions show a weaker-thanobserved cross-equator wind in the eastern Pacific, which induces a propagation of SST anomalies eastward and an EP-like El Niño event in April (1); note that in the observations, it is only weak central tropical Pacific warming). Such 
(a) Obs.

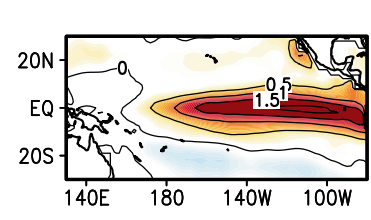

(b) ICM
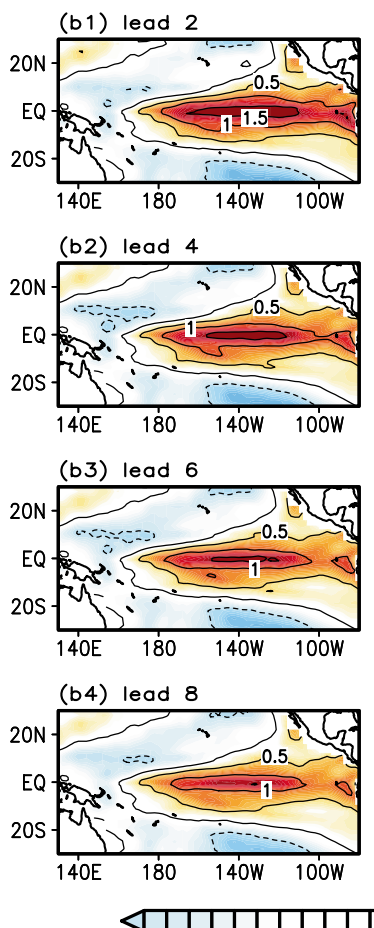

(c) NFSV-ICM
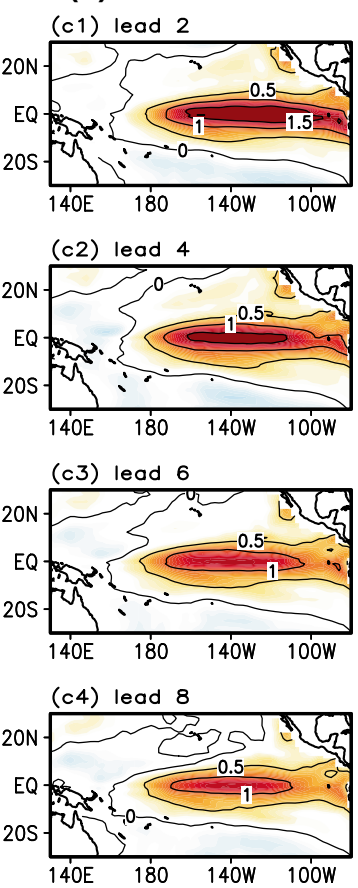

(d) Diff.
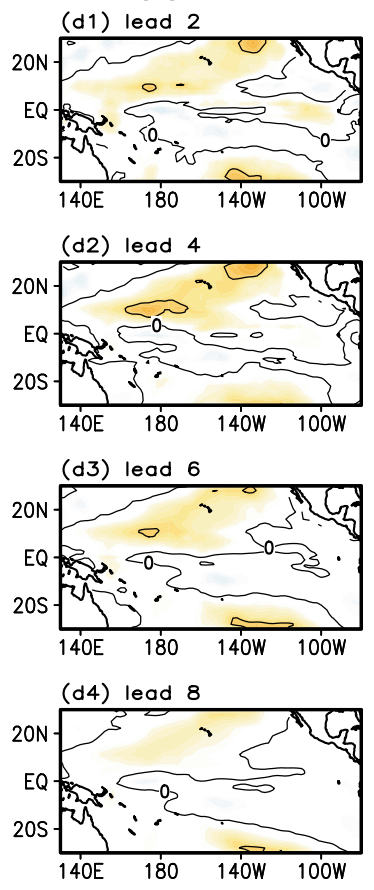

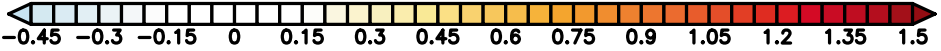

Fig. 4 As in Fig. 2, but for the EP-El Niño events

discrepancies are significantly reduced in the NFSV-ICM. The NFSV-ICM can well capture the local evolution characteristics of CP-El Niño events. Specifically, the NFSV-ICM shows weak initial warming in the central Pacific and strong convection in the central Pacific during the mature phase of the El Niño. Then, the SST anomalies are disrupted due to the strong cross-equator wind that pushes cold water to the central Pacific (Xie et al. 2018). Overall the NFSV-ICM is useful for predicting the development and the decay of the CP-El Niño.

Figure 6 displays the horizontal distributions of the evolutions of the EP-El Niño events, including observations and hindcasts with a 4-month lead time. Both the ICM and NFSV-ICM are able to predict the onset and the evolution of EP-El Niño events during spring and summer well. However, in October (0), the prediction using the ICM shows a cooler-than-observed ocean away from the equator, thus yielding an unrealistically high meridional gradient of the SST anomalies. Moreover, cyclonic anomalies prevail off the equator, thereby pumping the ocean and further cooling the surface ocean in the subtropical Pacific. Such an unrealistic meridional triple mode, presenting strong negative SST anomalies away from the equator and positive anomalies along the equator, is strengthened by air-sea interactions. Thus, the ICM predicts an El Niño event flanked by stronger-than-observed negative SST anomalies in January
(1). Although the ICM has skills in predicting the SST anomalies along the equator for EP-El Niño events, the subtropical SST evolution, as well as the surface wind, are not well predicted. In contrast, when using the NFSV-ICM, the unrealistic meridional triple mode is largely reduced, and the predictions regarding the development of EP-El Niño are closer to the observations including the SST anomalies and the surface winds. Neither the ICM nor the NFSV-ICM perform well in predicting the decay phase of the EP-El Niño events; the decay behavior of the El Niño is predicted to be slower than that in the observations. More precisely, the SST anomalies in the spring following the El Niño year generally disappear in the observations, while the warm anomalies in the eastern tropical Pacific still persist in both the ICM and NFSV-ICM. Especially in the ICM predictions, the notable SST anomalies that are larger than $1.5^{\circ} \mathrm{C}$ last from winter to the next spring (Fig. 5b). Comparing Figs. $5 \mathrm{~b}$ and $6 \mathrm{~b}$, it is clear that the ICM loses its skills in distinguishing the differences between the decay phases of EP- and CP-El Niño events and predicts quite similar behavior in April (1) in the EP- and CP-El Niño predictions, always showing significant SST anomalies in the eastern tropical Pacific. In contrast, as revealed in Figs. $5 \mathrm{c}$ and $6 \mathrm{c}$, the decay phases of EP- and CP-El Niño events are distinguishable using the NFSV-ICM.

In summary, the NFSV-ICM outperforms the ICM in the context of identifying the differences in El Niño types and 

(a) Observation
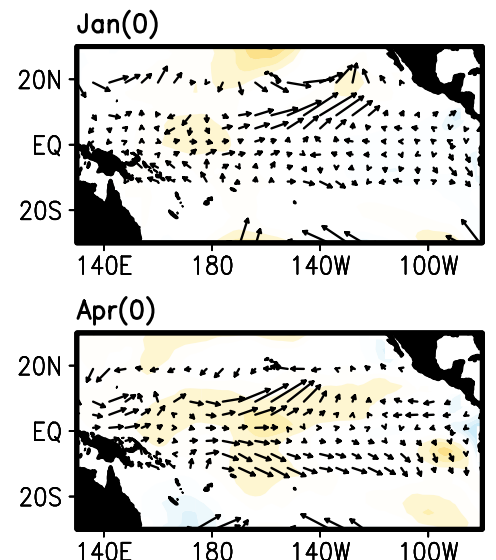

Jul(0)
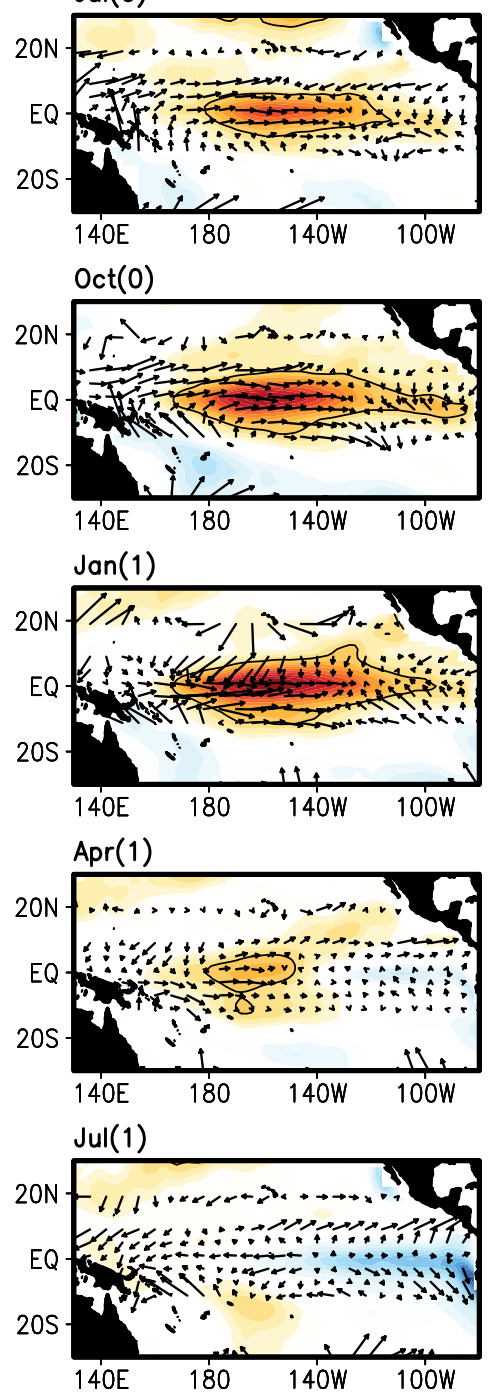

(b) $\mathrm{ICM}$
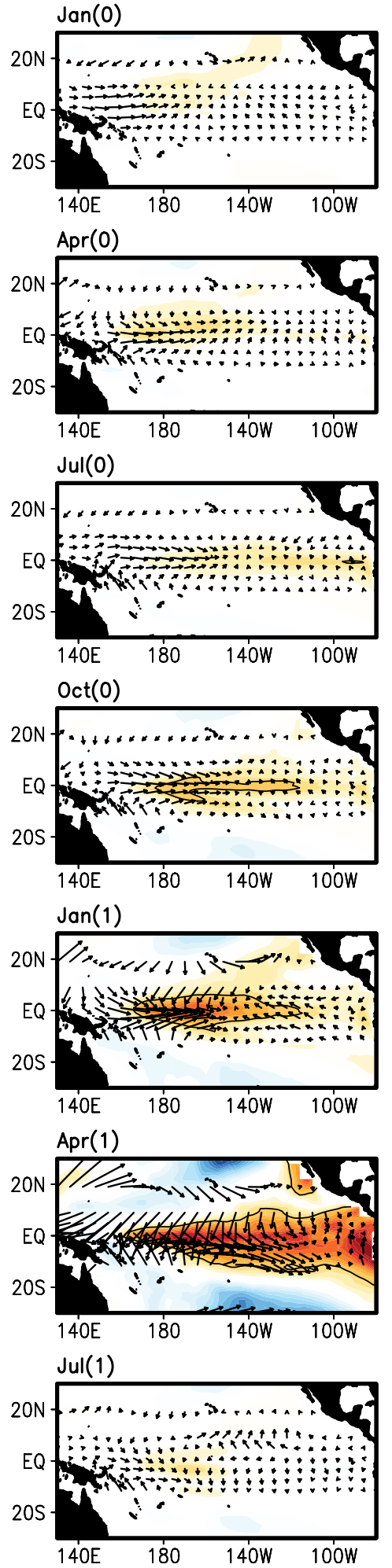

(c) NFSV-ICM
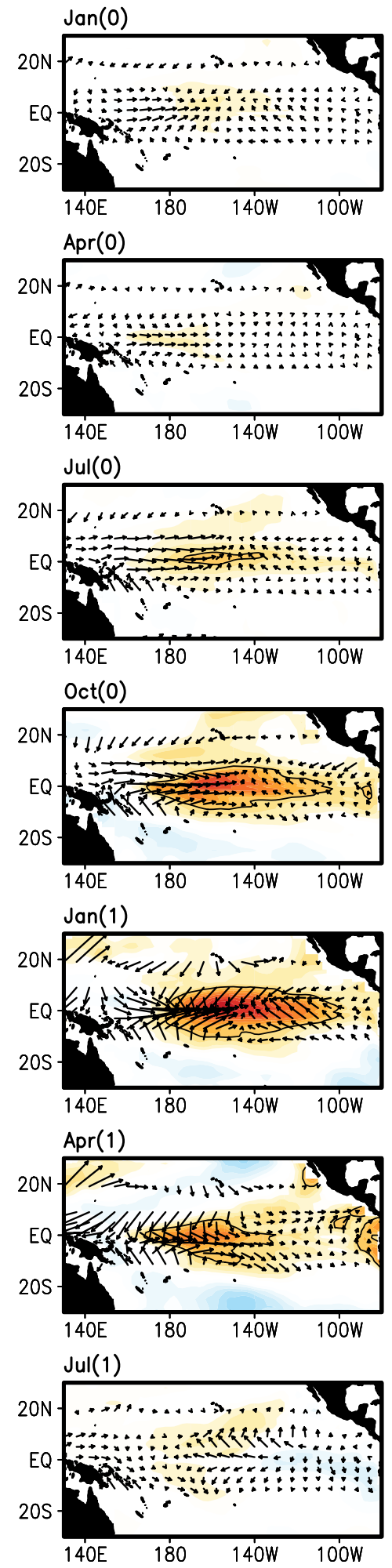

$\overrightarrow{0.4} \mathrm{dyn} \mathrm{cm}^{-0}$

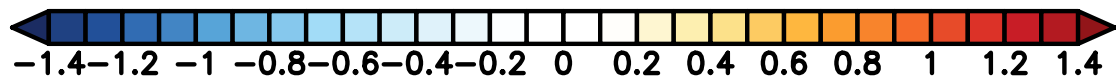


4 Fig. 5 Composite of the evolution of the wind stress and SST anomalies for the CP-El Niño events derived from the a observations and the b ICM and c NFSV-ICM predictions with a 4-month lead time, where " 0 " and " 1 " next to the calendar month denote the year when the El Niño event peaked and the following year, respectively. The contoured line represents $0.5^{\circ} \mathrm{C}$

dynamics in predictions. At the same time, the predictions of the evolution of the El Niño events with different types are also improved using the NFSV-ICM.

\section{The mechanisms leading to El Niño diversity}

As shown in the last section, the NFSV-based tendency perturbation plays a vital role in identifying El Niño diversity in predictions. In this section, we will try to explain how and why the NFSV-based tendency perturbation can improve the prediction skills of El Niño diversity.

Since model errors in the ICM are found to be casedependent, the NFSV-based tendency perturbations that describe the combined effect of model errors with various sources are also case-dependent [see Tao and Duan (2019)]. The diversity of the NFSV-based tendency perturbations that correct the ENSO predictions are directly related to the diversity of the El Niño in the NFSV-ICM predictions. To clarify this, the different spatial distributions of the predicted air-sea fields as well as the different ocean processes in the NFSV-ICM and ICM are explored.

\subsection{Distinct NFSV-based tendency perturbations for two types of El Niño}

Figure 7a shows the time-dependent NFSV-based tendency perturbations along the equator for $\mathrm{CP}-\mathrm{El}$ Niño predictions at 4-month lead times. The NFSV-based tendency perturbation is negative in the eastern tropical Pacific during the onset of El Niño. This indicates that the ICM has a positive tendency error for the SST anomalies in the eastern equatorial Pacific when predicting the onset stage of El Niño, which is offset by the NFSV-based tendency perturbation. When the CP-El Niño approaches the mature phase, the NFSV-based tendency perturbation experiences a change of phase leading to a warming effect in the central-eastern tropical Pacific, which indicates that the ICM tends to have negative tendency errors of SST anomalies in these regions when predicting the mature phase of El Niño. By examining the total effect of the NFSV-based tendency perturbations during CP-El Niño development, a net warming effect on the SST tendency is found over the central tropical Pacific (Fig. 8a), enhancing the development of positive SST anomalies in the central tropical Pacific. This net warming effect forces the model to yield a central Pacific warming event. After the event peak, the NFSV-based tendency perturbations feature negative anomalies with high values in the central-eastern tropical Pacific [Fig. 7a, after January (1)], which induces a quick dampening of the SST anomalies and helps to terminate these events.

The NFSV-based tendency perturbations for the EP-El Niño predictions are different from those for the CP-El Niño predictions. To illustrate them, we show a composite of the NFSV-based tendency perturbations in Fig. $8 \mathrm{~b}$ in the different months of the year when the EP-El Niño reaches its mature phase. The NFSV-based tendency perturbations are positive in the subtropical Pacific, inducing ocean warming of the ocean and reducing the cooling bias off the equator in the ICM. In addition, the NFSV-based tendency perturbations characterized by negative anomalies over the central Pacific and positive anomalies over the eastern Pacific tend to shift the predicted SST anomalies substantially eastward (Fig. 9a). For the decay phase predictions, the NFSV-based tendency perturbations are negative, offsetting the positive tendency errors in the SST and helping to terminate the El Niño events within a realistic time.

\subsection{The physics of the NFSV-based tendency perturbation modulating CP- and EP-EI Niño formulation by coupling processes}

The modulation of the SST evolution by the NFSV-based tendency perturbation influences the air-sea interactions. The differences between the ICM and NFSV-ICM predictions in the air-sea coupling conditions of the CP-El Niño events are displayed in Fig. 7. As a response to the cooling effect of the negative NFSV-based tendency perturbation occurring in the central-eastern tropical Pacific (Fig. 7a), an anomalous easterly wind occurs in the western tropical Pacific (Fig. 7b). This weakens the westerly wind anomaly near the dateline during the onset of the CP-El Niño event and favors the release of ocean heat in the mixed layer [see Fig. 7c, in Feb (0)]. This anomalous easterly wind moves eastward over time and enhances the cross-equator wind in the eastern tropical Pacific in July; see Fig. 5b and c. In the meantime, the positive NFSV-based tendency perturbations emerging in the central Pacific tend to induce anomalous westerly winds in the western tropical Pacific in August (Fig. 7a, b). These anomalous easterly winds in the eastern tropical Pacific and anomalous westerly winds in the western tropical Pacific induced by NFSV-based tendency perturbations affect the ocean and can result in warm water accumulation in the central tropical Pacific, as indicated by the positive sea level (SL) anomalies and subsurface temperature (Te) (Fig. 7c, d). In addition, the strongly positive NFSV-based tendency perturbations occurring in the central-eastern tropical Pacific result in 

(a) Observation
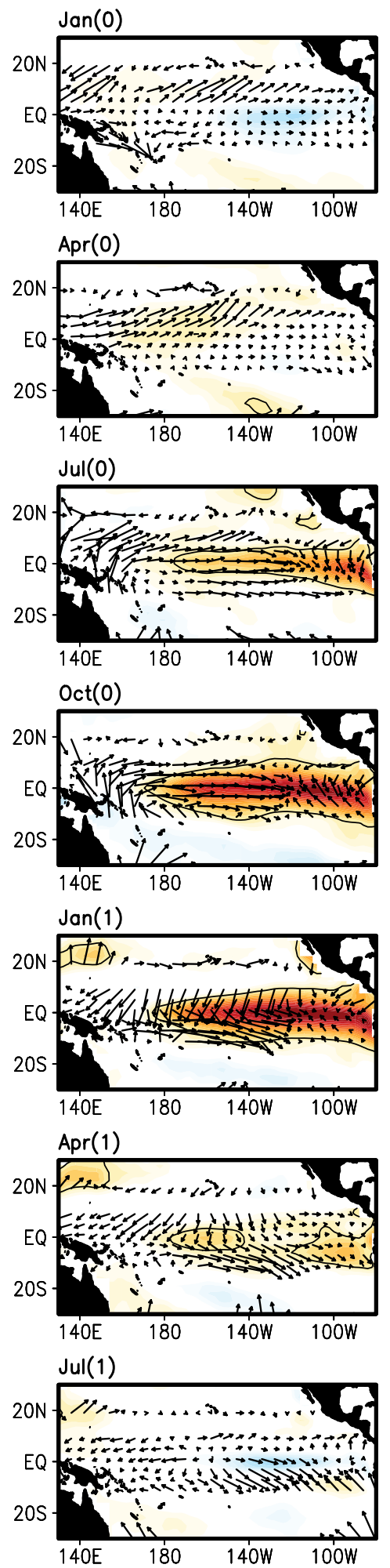

(b) $\mathrm{ICM}$
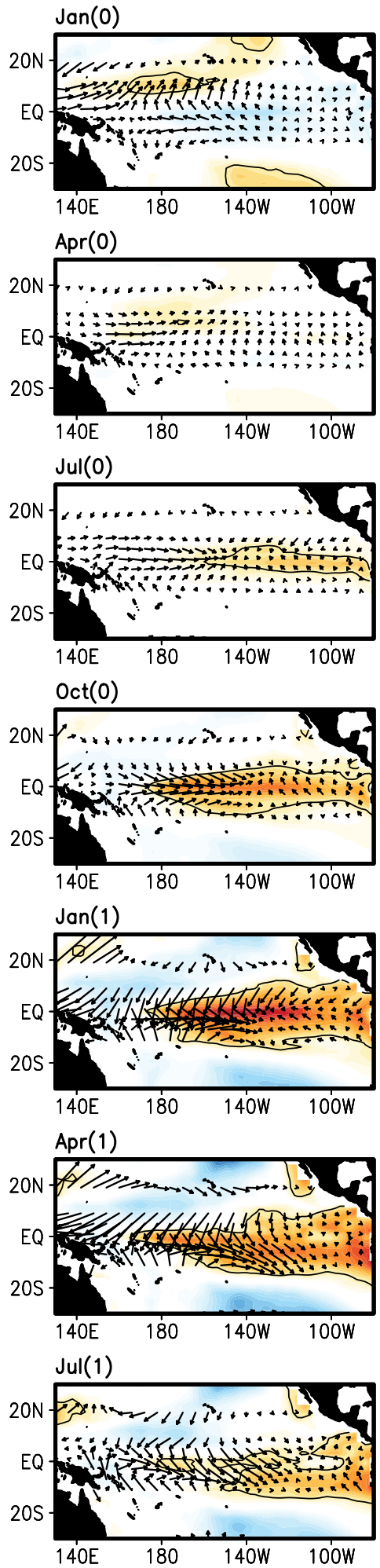

(c) NFSV-ICM
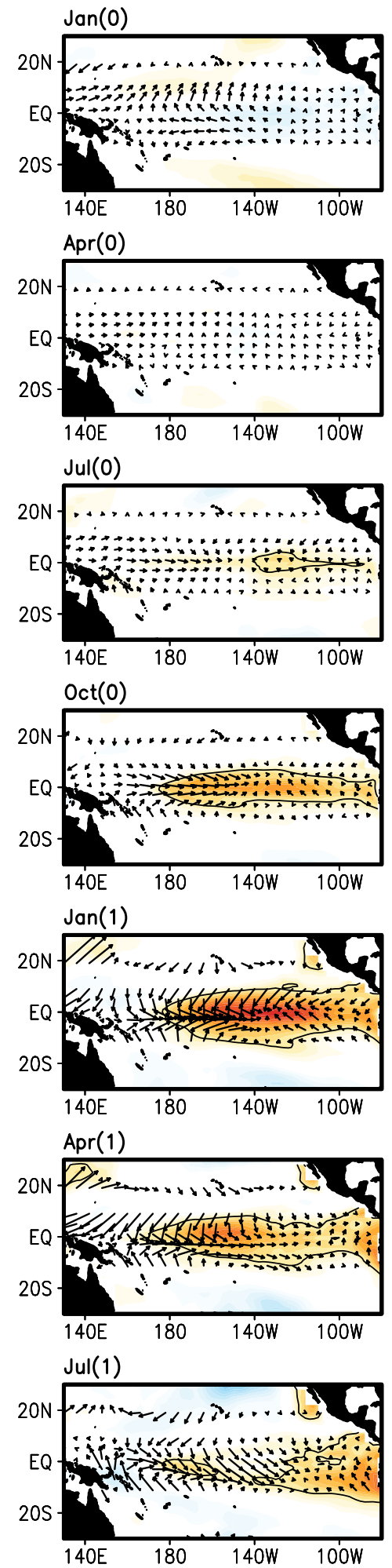

$\overrightarrow{0.6} \mathrm{dyn} \mathrm{cm}^{-6}$

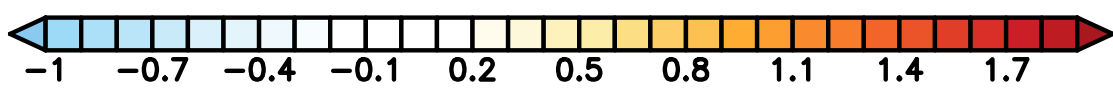

Fig. 6 As in Fig. 5, but for the EP-El Niño events 
(a) NFSV-tendency perturbation

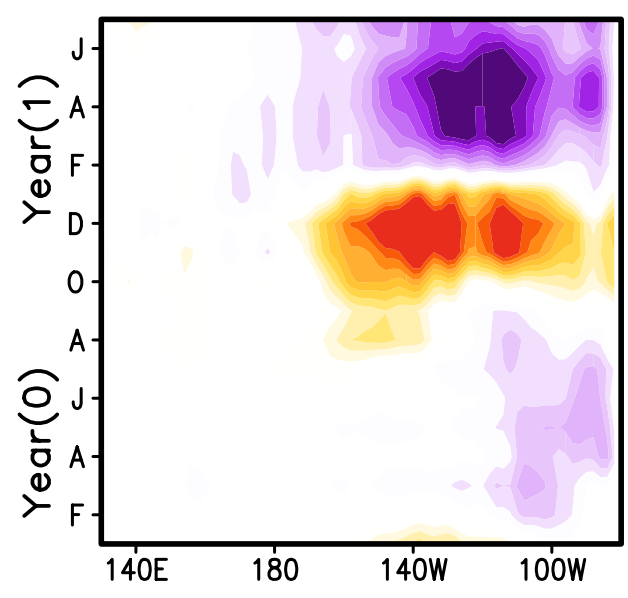

(c) SL anomalies

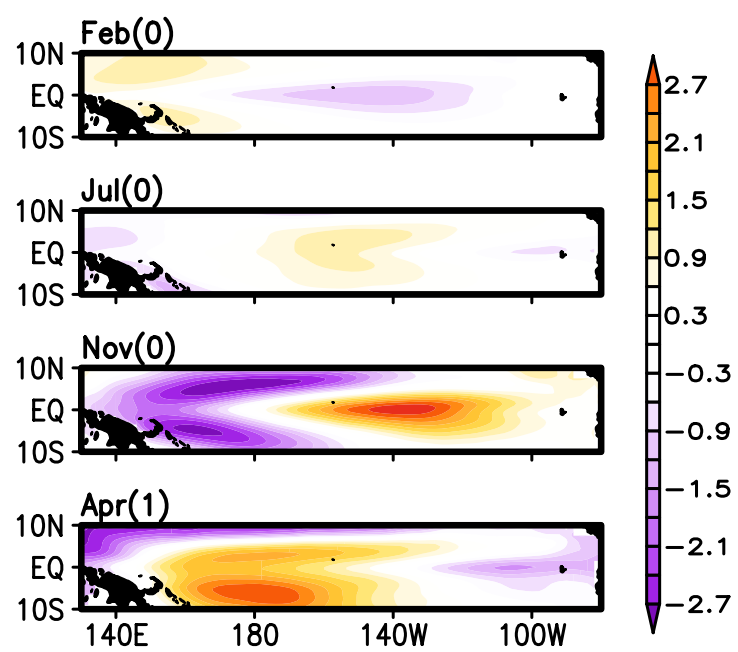

Fig. 7 The longitude-time section of a the NFSV-based tendency perturbation (unit: $10^{-6}{ }^{\circ} \mathrm{C} / \mathrm{s}$ ), b the differences in the equatorial zonal wind stress (unit: dyn $\mathrm{cm}^{-2}$ ) in the CP-El Niño predictions with a

westerly wind anomalies associated with a significantly amplified CP-El Niño after October (0), which enhances the strength of the warming effect and offsets the discrepancy in the intensity of the El Niño event in the ICM. As a result, the NFSV-ICM provides a more realistic CP-El Niño event than the ICM in terms of its amplitude and horizontal structure (Fig. 2). For the termination of the CP-El Niño events, the NFSV-based estimation of the negative tendency perturbations occurring in the central-eastern tropical Pacific during the following spring [e.g., February (1)-June (1) in Fig. 7a] induces stronger trade winds and offsets the discrepancy in trade winds in the ICM, inducing a quickly dampened CP-El Niño with a more realistic termination [see Fig. 5 in July (1)]. Clearly, in terms of the (b) Zonal wind stress

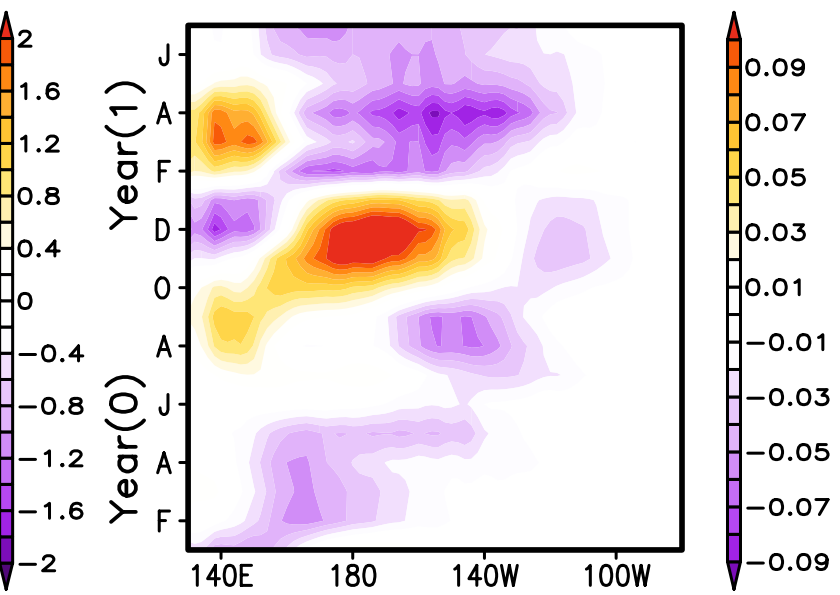

(d) Te anomalies

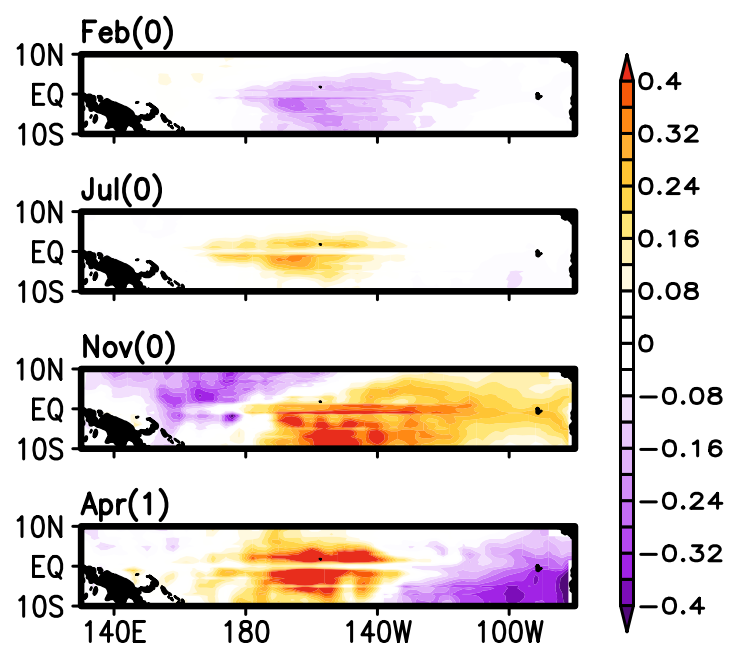

4-month lead time between the NFSV-ICM and ICM, and the related horizontal differences in the $\mathbf{c}$ sea level (SL; unit: $\mathrm{cm}$ ) and $\mathbf{d}$ subsurface temperature $\left(\mathrm{Te}\right.$; unit: $\left.{ }^{\circ} \mathrm{C}\right)$

air-sea coupling, the NFSV-based tendency perturbations exert positive influences both in the atmosphere and the ocean for the improvement of the CP-El Niño predictions.

For the EP-El Niño events, the differences in the related air-sea coupling states between the ICM and NFSV-ICM predictions are presented in Fig. 9. Clearly, the westerly wind anomaly in the NFSV-ICM, compared to that in the ICM, is much weaker in the western tropical Pacific due to the cooling effect of the negative NFSV-based tendency perturbations in the eastern tropical Pacific during the onset of El Niño. The weakened westerly anomalies reduce the thermocline effect on SST and induce a cooling effect on the eastern tropical Pacific SST, as indicated by the negative SL anomalies in the eastern tropical Pacific (Fig. 9c). This 
(a) CP EI Nino

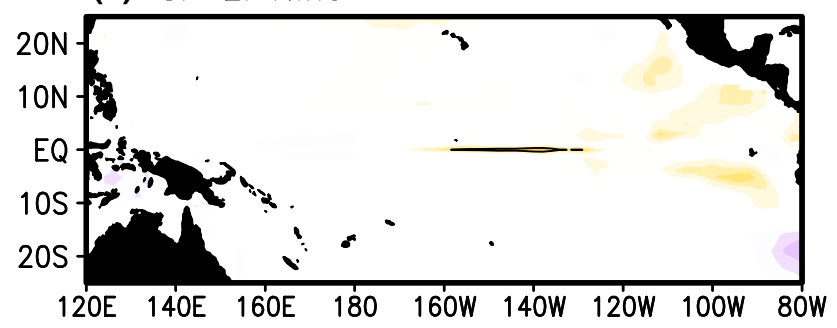

(b) EP El Nino

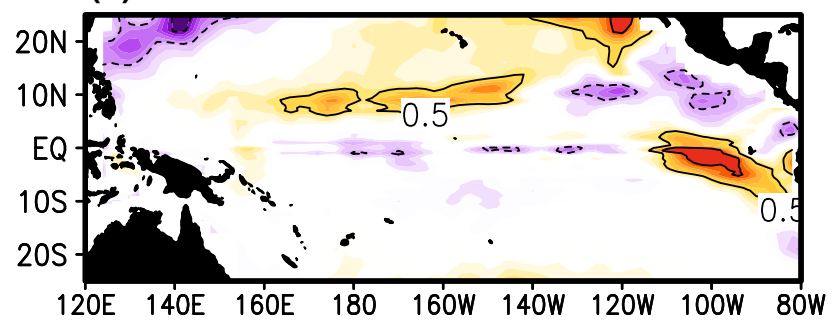

Fig. 8 Composites of the NFSV-based tendency perturbations for the growth phase [from January (0) to December (0)] of a CP-El Niño and b EP-El Niño events. The contour interval is $0.5 \times 10^{-6}{ }^{\circ} \mathrm{C} / \mathrm{s}$ air-sea cooling effect is unrealistically strong. Even if the positive NFSV-based tendency perturbations occurring in the eastern tropical Pacific induced warming effects on SST in winter, they would not fully eliminate the deviation of such cooling effects on the eastern tropical Pacific. Consequently, the predictions for EP-El Niño made by the NFSVICM are only slightly improved (Fig. 4). During the decay phase of the EP-El Niño, the westerly wind is enhanced in the western Pacific as a response to the warming effect of the NFSV-based tendency perturbations in the western tropical Pacific (Fig. 9b). The anomalous westerlies force the ocean and deepen the thermocline with a warming effect on the ocean surface counteracting the termination of EP-El Niño events [Fig. 9c, $d$ in April (1)]. Thus, even though a strong cooling trend is induced by the negative NFSV-based tendency perturbations (Fig. 9a), termination is delayed by the air-sea coupling-induced warming effect. From the above, the NFSV-based tendency perturbation-induced air-sea modulation tends to weaken the direct effect of the NFSV-based tendency perturbations on EP-El Niño predictions. Therefore, the prediction of the EP-El Niño evolution is slightly improved when using the NFSV-ICM.
Fig. 9 As in Fig. 7, but for the EP-El Niño events (a) NFSV-tendency perturbation

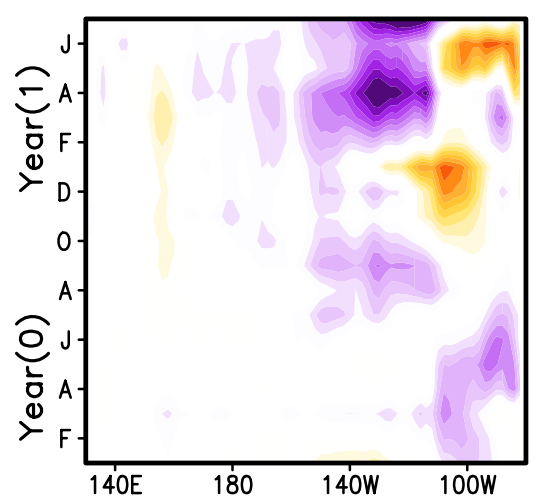

(c) SL anomalies
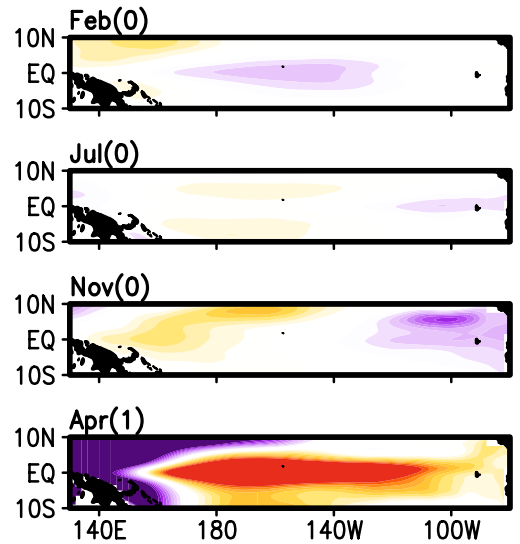
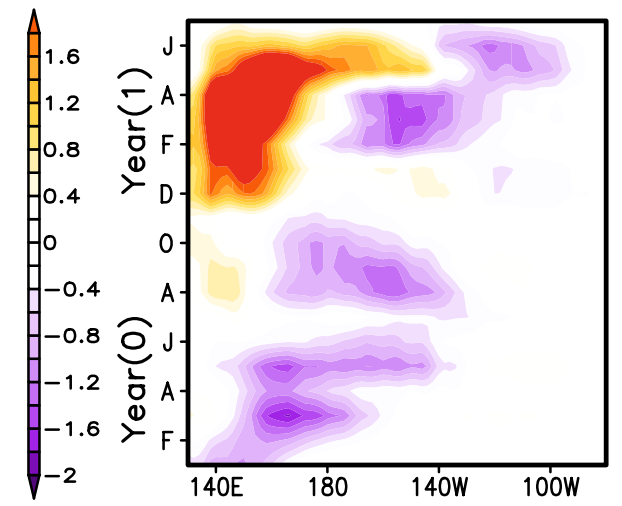

(d) Te anomalies

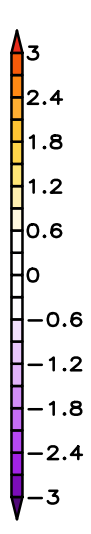

(b) Zonal wind stress
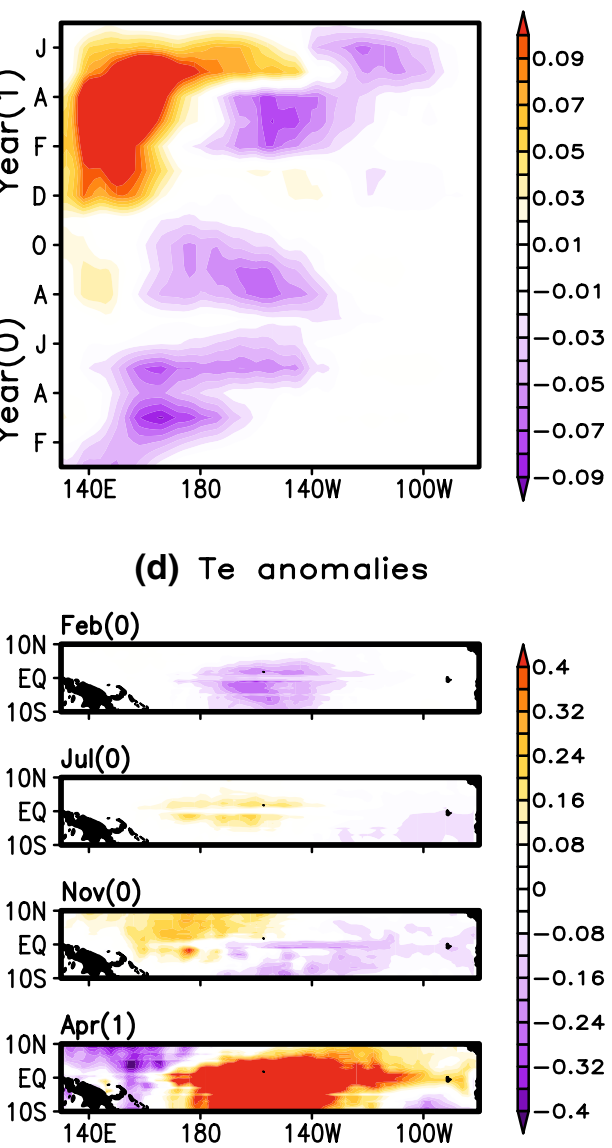


\subsection{The role of ocean heat transport in formulating CP- and EP-EI Niño in predictions}

The adjustment in air-sea coupling due to NFSV-based tendency perturbations is also reflected in ocean processes. To quantify the effects of the NFSV-based tendency perturbations on the dynamics of the tropical ocean, heat budget analyses are implemented by taking the differences in the advection terms of the SST equation between the NFSVICM and ICM. Focusing on the development of El Niño events, related calculations were conducted in the Niño3.4 region during the El Niño period, from October (0) to December (0).

The differences in the heat budget between the NFSVICM and ICM for the CP-El Niño predictions are listed in Table 2. Three terms are found to dominate the warming tendency in the central tropical Pacific, i.e., the meridional advection by the mean current of the anomalous SST $\left(-\bar{v} \frac{\partial T^{\prime}}{\partial \mathrm{y}}\right)$, zonal advection by the anomalous current of the mean SST $\left(-u^{\prime} \frac{\partial \bar{T}}{\partial \mathrm{x}}\right)$, and zonal advection by the mean current of the anomalous SST $\left(-\bar{u} \frac{\partial T^{\prime}}{\partial \mathrm{x}}\right)$. The term $-\bar{v} \frac{\partial T^{\prime}}{\partial \mathrm{y}}$ plays a role in adjusting the poleward extension of SST anomalies. This term has a positive value, indicating that the ICM predictions display a relatively narrow meridional extent of the SST anomaly while the NFSV-ICM predictions present a CP-El Niño event with a realistic meridional extent (Fig. 2b, c). The term $-u^{\prime} \frac{\partial T}{\partial x}$, known as the zonal advection feedback, also shows a positive value; this implies that the ICM exhibits much weaker zonal advection feedback while the NFSVICM presents stronger feedback. This term plays an important role in the formation of CP-El Niño (Kug et al. 2009; Yu et al. 2010; Duan et al. 2014). Therefore, the strong zonal advection feedback in the NFSV-ICM may explain why the NFSV-ICM can capture the main characteristics of the CP-El Niño events. At the same time the NFSV-ICM

Table 2 Differences in the heat budget (unit: ${ }^{\circ} \mathrm{C} / \mathrm{month}$ ) in the Niño3.4 area during the period from October $(0)$ to December $(0)$ for the CP-El Niño events

\begin{tabular}{lrlrr}
\hline & Term 1 & Term 2 & Term 3 & \multicolumn{1}{c}{ Total } \\
\hline Zonal advection & 1.40 & 3.17 & -1.32 & 3.25 \\
Meridional advection & 5.09 & 0.19 & 0.01 & 5.10 \\
Vertical advection & -10.56 & 0.13 & -0.11 & -10.54 \\
dT/dt & & & & 9.5 \\
\hline
\end{tabular}

The composite values are calculated for the 4-month hindcasts using the NFSV-ICM and ICM. The linear advection terms are terms 1 and 2 , which represent the advection by the mean current of the anomalous SST (i.e., $-\bar{u} \frac{\partial T^{\prime}}{\partial \mathrm{x}},-\bar{v} \frac{\partial T^{\prime}}{\partial \mathrm{y}}$ and $-\bar{w} \frac{\partial T^{\prime}}{\partial \mathrm{z}}$ ) and the advection by the anomalous current of the mean SST (i.e., $-u^{\prime} \frac{\partial \bar{T}}{\partial \mathrm{x}},-v^{\prime} \frac{\partial \bar{T}}{\partial \mathrm{y}}$ and $-w^{\prime} \frac{\partial \bar{T}}{\partial z}$ ), respectively; term 3 is the nonlinear advection term (i.e., $-u^{\prime} \frac{\partial T^{\prime}}{\partial \mathrm{x}}$, $-v^{\prime} \frac{\partial T^{\prime}}{\partial \mathrm{y}}$ and $\left.-w^{\prime} \frac{\partial T^{\prime}}{\partial \mathrm{z}}\right)$ possesses a much weaker vertical advection of the anomalous SST $\left(-\bar{w} \frac{\partial T^{\prime}}{\partial z}\right)$ when predicting the CP-El Niño, which indicates that the NFSV-ICM displays a weaker thermocline feedback on the SST during the CP-El Niño prediction. This emphasizes the secondary role of thermocline feedback in the formation of the CP-El Niño and agrees with the results shown in Yu et al. (2010) and Duan et al. (2014).

It is of interest to realize that the NFSV-based tendency perturbation-induced changes in the ocean processes for EP-El Niño events are almost opposite to those for CP-El Niño events. As shown in Table 3, the effect of the vertical advection by the mean upwelling of the anomalous SST $\left(-\bar{w} \frac{\partial T^{\prime}}{\partial z}\right)$ is enhanced in the NFSV-ICM, while the effects of the zonal advections indicated by $-u^{\prime} \frac{\partial T}{\partial \mathrm{x}}$ and $-\bar{v} \frac{\partial T^{\prime}}{\partial \mathrm{y}}$ are reduced. These results indicate that the NFSV-ICM tends to enhance the thermocline feedback and weaken the zonal advection feedback. In fact, previous studies have demonstrated that thermocline feedback dominates the process of EP-El Niño formation (Kug et al. 2009, 2010). This suggests that the strengthening of the thermocline feedback is most likely the reason why the NFSV-ICM provides a much more realistic EP-El Niño than the ICM.

\section{Conclusion and discussion}

Tao and Duan (2019) used the NFSV-assimilation approach to correct the ICM ENSO model and reformulated an NFSVICM ENSO forecast system. They showed that the NFSVICM possesses much higher forecast skill of Niño3.4 index associated with ENSO events than the ICM. The present study further explores the ability of the NFSV-ICM to identify different El Niño types in predictions and identifies the origin of these improvements as well as the role of the NFSV-based tendency perturbations. The results show that the predictions by the NFSV-ICM capture the warming center position and strength of the CP-El Niño event well, while the ICM describes a weaker-than-observed El Niño event with a warming center located in the tropical east Pacific rather than in the central Pacific. For EP-El Niño events, the NFSV-ICM reduces the cold bias in the subtropical Pacific presented in the ICM so that the large-scale characteristics of EP-El Niño events can be suitably predicted

Table 3 As in Table 2, but for the EP-El Niño events

\begin{tabular}{lrrrr}
\hline & Term 1 & Term 2 & Term 3 & \multicolumn{1}{c}{ Total } \\
\hline Zonal advection & 1.25 & -2.67 & 0.80 & -0.61 \\
Meridional advection & -5.50 & -0.20 & 3.04 & -2.75 \\
Vertical advection & 1.81 & 0.03 & -0.17 & 1.61 \\
dT/dt & & & & -2.60 \\
\hline
\end{tabular}


using the NFSV-ICM. In terms of the types of El Niño, the NFSV-ICM is able to distinguish the main characteristics of the two types of El Niño with a two-season lead time, while the ICM tends to output a single pattern of El Niño (i.e., the EP-El Niño) beyond a one-season lead time.

The NFSV-based tendency perturbation corrects for atmospheric, oceanic, and its own interactions in the ICM and makes the reformulated NFSV-ICM able to capture the characteristics of El Niño diversities. In particular, due to the NFSV-based tendency perturbations, the wind convergence in the central Pacific is enhanced in the NFSV-ICM during predictions of CP-El Niño events, while the westerly anomalies are shifted eastward during predictions of the EP-El Niño events. Thus, the wind anomaly-induced SST anomaly positions are properly captured for both types of El Niño in the NFSV-ICM. On the other hand, the associated ocean processes are also corrected depending on the El Niño type in the NFSV-ICM. In EP-El Niño predictions, the NFSV-ICM generates a stronger thermocline feedback and a weaker zonal advection feedback than the ICM. Conversely, the NFSV-ICM produces a stronger zonal advection feedback and a weak thermocline feedback for CP-El Niño predictions. The dominant role of thermocline feedback and zonal advection feedback in formulating EP- and CP-El Niño events, is well documented (Kug et al. 2009, 2010; Yu et al. 2010; Duan et al. 2014), and NFSV-based tendency perturbations correct these two feedback processes in the ICM so that the NFSV-ICM has ability to identify CP- and EP-El Niño events in forecasts.

Since the NFSV-based tendency perturbation represents the combined effect of model errors from different sources, it can be viewed as a climate forcing missing in the ICM model. For instance, the ICM only reproduces the tropical Pacific and not the extratropical forcing effect; now it is corrected by the NFSV-based tendency perturbation in the NFSV-ICM. This supports the results of Yu and Kim (2011) and Hou et al. (2019) who show that the North Pacific variability dominates the development of the CP-El Niño. The NFSV-based tendency perturbations therefore include the impact of the extratropical forcing on El Niño diversities. This also suggests that more focus is needed on the simulation of extratropical climate variability in order to appropriately reproduce the state of the tropical Pacific state.

The NFSV-ICM dose have limitations. The NFSV-based tendency perturbation is dependent on the optimization periods and models as well as on the statistical method building the relationship between SST and NFSV-based tendency perturbations. That is, the NFSV-based tendency perturbation derived from the ICM cannot be used used in other models. Especially for a fully coupled model, the NFSVbased tendency perturbation model could be established and coupled not only to ocean component but also to atmospheric component due to the effect of the different scales in the atmosphere and ocean. This issue needs to be paid attention and resolved in the future. The present study provides guidance for the application of the NFSV-assimilation to more sophisticated coupled models and a useful platform for studying the essential features of ENSO diversity and its predictability.

Acknowledgements The authors appreciate anonymous reviewers for their constructive comments and suggestions. This work was supported by the National Natural Science Foundation of China (Grant Nos. 41930971, 41525017 and 41690124).

Open Access This article is licensed under a Creative Commons Attribution 4.0 International License, which permits use, sharing, adaptation, distribution and reproduction in any medium or format, as long as you give appropriate credit to the original author(s) and the source, provide a link to the Creative Commons licence, and indicate if changes were made. The images or other third party material in this article are included in the article's Creative Commons licence, unless indicated otherwise in a credit line to the material. If material is not included in the article's Creative Commons licence and your intended use is not permitted by statutory regulation or exceeds the permitted use, you will need to obtain permission directly from the copyright holder. To view a copy of this licence, visit http://creativecommons.org/licenses/by/4.0/.

\section{Reference}

Ashok K, Behera SK, Rao SA, Weng HY, Yamagata T (2007) El Niño Modoki and its possible teleconnection. J Geophys Res. https:// doi.org/10.1029/2006jc003798

Barkmeijer J, Iversen T, Palmer TN (2003) Forcing singular vectors and other sensitive model structures. QJR Meteorol Soc 129:2401-2423. https://doi.org/10.1256/qj.02.126

Capotondi A (2013) El Niño diversity in the NCAR CCSM4 climate model. J Geophys Res-Oceans 118:4755-4770. https://doi. org/10.1002/jgrc.20335

Chen D, Cane MA, Zebiak SE, Canizares R, Kaplan A (2000) Bias correction of an ocean-atmosphere coupled model. Geophy Res Lett 27:2585-2588. https://doi.org/10.1029/1999g1011078

Chiang JCH, Vimont DJ (2004) Analogous Pacific and Atlantic meridional modes of tropical atmosphere-ocean variability. J Climate 17:4143-4158. https://doi.org/10.1175/JCLI4953.1

Choi J, An SI, Kug JS, Yeh SW (2011) The role of mean state on changes in El Nio's flavor. Clim Dynam 37:1205-1215. https:// doi.org/10.1007/s00382-010-0912-1

Duan WS, Zhou FF (2013) Non-linear forcing singular vector of a twodimensional quasi-geostrophic model. Tellus A 65:256-256. https ://doi.org/10.3402/tellusa.v65i0.18452

Duan WS, Hu JY (2016) The initial errors that induce a significant "spring predictability barrier" for El Niño events and their implications for target observation: results from an earth system model. Clim Dynam 46:3599-3615. https://doi.org/10.1007/s0038 2-015-2789-5

Duan WS, Tian B, Xu H (2014) Simulations of two types of El Niño events by an optimal forcing vector approach. Clim Dynam 43:1677-1692. https://doi.org/10.1007/s00382-013-1993-4

Duan WS, Wei C (2013) The "spring predictability barrier" for ENSO predictions and its possible mechanism: results from a fully coupled model. Int J Climatol 33(5):1280-1292. https://doi. org/10.1002/joc.3513 
Gao C, Wu XR, Zhang R-H (2016) Testing a four-dimensional variational data assimilation method using an improved intermediate coupled model for ENSO analysis and prediction. Adv Atmos Sci, 33, 875-888. https://doi.org/10.1007/s00376-016-5249-1

Gao C, Zhang R-H (2017) The roles of atmospheric wind and entrained water temperature (Te) in the second-year cooling of the 20102012 La Niña event. Clim Dynam 48:597-617. https://doi. org/10.1007/s00382-016-3097-4

Gao C, Zhang RH, Wu XR, Sun JC (2018) Idealized Experiments for Optimizing Model Parameters Using a 4D-Variational Method in an Intermediate Coupled Model of ENSO. Adv Atmos Sci 35:410-422. https://doi.org/10.1007/s00376-017-7109-z

Ham YG, Kug JS (2012) How well do current climate models simulate two types of El Niño? Clim Dynam 39:383-398. https://doi. org/10.1007/s00382-011-1157-3

Hendon HH, Lim E, Wang GM, Alves O, Hudson D (2009) Prospects for predicting two flavors of El Niño. Geophys Res Lett. https:// doi.org/10.1029/2009g1040100

Hou MY, Duan WS, W. and Zhi XF (2019) Season-dependent predictability barrier for two types of El Niño revealed by an approach to data analysis for predictability. Clim Dynam 53:5561-5581. https ://doi.org/10.1007/s00382-019-04888-w

Hu JY, Duan WS (2016) Relationship between optimal precursory disturbances and optimally growing initial errors associated with ENSO events: Implications to target observations for ENSO prediction. J Geophys Res Oceans 121:2901-2917. https://doi. org/10.1002/2015JC011386

Jeong HI, Coauthors (2012) Assessment of the APCC coupled MME suite in predicting the distinctive climate impacts of two flavors of ENSO during boreal winter. Clim Dynam 39:475-493. https:// doi.org/10.1007/s00382-012-1359-3

Ji. M, Leetmaa A, Kousky VE (1996) Coupled model forecasts of ENSO during the 1980 and 1990s at the National Centers for Environmental Prediction. J Clim 9:3105-3120. https://doi. org/10.1175/1520-0442(1996)009<3105:CMPOED>2.0.CO;2

Jin EK, Coauthors (2008) Current status of ENSO prediction skill in coupled ocean-atmosphere models. Clim Dynam 31:647-664. https://doi.org/10.1007/s00382-008-0397-3

Kalnay E, Coauthors (1996) The NCEP/NCAR 40-year reanalysis project. B Am Meteorol Soc 77:437-471. https://doi. org/10.1175/1520-0477(1996)077<0437:Tnyrp>2.0.Co;2

Kao HY, Yu JY (2009) Contrasting Eastern-Pacific and Central-Pacific types of ENSO. J Clim 22:615-632. https://doi.org/10.1175/2008J CLI2309.1

Kim ST, Yu JY, Kumar A, Wang H (2012) Examination of the two types of ENSO in the NCEP CFS model and its extratropical associations. Mon Weather Rev 140:1908-1923. https://doi. org/10.1175/Mwr-D-11-00300.1

Kug JS, Jin FF, An SI (2009) Two Types of El Niño Events: cold Tongue El Niño and Warm Pool El Niño. J Clim 22:1499-1515. https://doi.org/10.1175/2008JCLI2624.1

Kug JS, Choi J, An SI, Jin FF, Wittenberg AT (2010) Warm pool and cold Tongue El Niño events as simulated by the GFDL 2.1 coupled GCM. J Clim 23:1226-1239. https://doi.org/10.1175/2009j cli3293.1

Lee RW-K, Tam C-Y, Sohn S-J, Ahn J-B (2018) Predictability of two types of El Niño and their climate impacts in boreal spring to summer in coupled models. Clim Dynam 51:4555-4571. https:// doi.org/10.1007/s00382-017-4039-5

Mu B, Ren J, Yuan S, Zhang RH, Chen L, Gao C (2019) The optimal precursors for ENSO events depicted using the Gradient-definition-based method in an intermediate coupled model. Adv Atmos Sci 36(12):1381-1392
Moore AM, Kleeman R (1996) The dynamics of error growth and predictability in a coupled model of ENSO. Quart J R Meteorol Soc 534:1405-1446. https://doi.org/10.1002/qj.49712253409

Nicolis C, Perdigao R, Vannitsem S (2009) Dynamics of prediction errors under the combined effect of initial condition and model errors. J Atmos Sci 66:766-778. https://doi.org/10.1175/2008J AS2781.1

Ren HL, Scaife AA, Dunstone N, Tian B, Liu Y, Ineson S, Lee JY, Smith D, Liu CZ, Thompson V, Vellinga M, MacLachlan C (2018a) Seasonal predictability of winter ENSO types in operational dynamical model predictions. Clim Dynam. https://doi. org/10.1007/s00382-018-4366-1

Ren HL, Jin FF (2011) Niño indices for two types of ENSO. Geophys Res Lett. https://doi.org/10.1029/2010gl046031

Ren HL, Zuo JQ, Deng Y (2018b) Statistical predictability of Niño indices for two types of ENSO. Clim Dynam. https://doi. org/10.1007/s00382-018-4453-3

Ren HL, Jin FF, Tian B, Scaife AA (2016) Distinct persistence barriers in two types of ENSO. Geophys Res Lett 43:10973-10979. https ://doi.org/10.1002/2016gl071015

Smith TM, Reynolds RW, Peterson TC, Lawrimore J (2008) Improvements to NOAA's historical merged land-ocean surface temperature analysis (1880-2006). J Clim 21:2283-2296. https://doi. org/10.1175/2007JCLI2100.1

Tao LJ, Zhang RH, Gao C (2017) Initial error-induced optimal perturbations in ENSO predictions, as derived from an intermediate coupled model. Adv Atmos Sci 34:791-803. https://doi. org/10.1007/s00376-017-6266-4

Tao LJ, Gao C, Zhang RH (2018) ENSO predictions in an intermediate coupled model influenced by removing initial condition errors in sensitive areas: a target observation perspective. Adv Atmos Sci 35:853-867. https://doi.org/10.1007/s00376-017-7138-7

Tao LJ, Duan WS (2019) Using a nonlinear forcing singular vector approach to reduce model error effects in ENSO forecasting. Weather Forecast 34:1321-1342. https://doi.org/10.1175/ WAF-D-19-0050.1

Taschetto AS, Sen Gupta A, Jourdain NC, Santoso A, Ummenhofer CC, England MH (2014) Cold tongue and warm pool ENSO events in CMIP5: mean state and future projections. J Clim 27:2861-2885. https://doi.org/10.1175/Jcli-D-13-00437.1

Tian B, Duan WS (2016) Comparison of the initial errors most likely to cause a spring predictability barrier for two types of El Niño events. Clim Dynam 47:779-792. https://doi.org/10.1007/s0038 2-015-2870-0

Vannitsem S, Toth Z (2002) Short-term dynamics of model errors. J Atmos Sci 59:2594-2604. https://doi.org/10.1175/15200469(2002)059<2594:STDOME > 2.0.CO;2

Xie SP, Philander SGH (1994) A coupled ocean-atmosphere model of relevance to the Itcz in the Eastern Pacific. Tellus A 46:340-350. https://doi.org/10.1034/j.1600-0870.1994.t01-1-00001.x

Xie SP, Peng QH, Kamae Y, Zheng XT, Tokinaga H, Wang DX (2018) Eastern Pacific ITCZ Dipole and ENSO Diversity. J Clim 31:4449-4462. https://doi.org/10.1175/JCLI-D-17-0905.1

Yang S, Jiang XW (2014) Prediction of Eastern and Central Pacific ENSO events and their impacts on East Asian climate by the NCEP climate forecast system. J Clim 27:4451-4472. https://doi. org/10.1175/Jcli-D-13-00471.1

Yu JY, Kim ST (2010) Identification of Central-Pacific and EasternPacific types of ENSO in CMIP3 models. Geophys Res Lett. https ://doi.org/10.1029/2010g1044082

Yu JY, Kim ST (2011) Relationships between extratropical sea level pressure variations and the Central Pacific and Eastern Pacific types of ENSO. J Clim 24:708-720. https://doi.org/10.1175/2010J CLI3688.1 
Yu JY, Kao HY, Lee T (2010) Subtropics-related interannual sea surface temperature variability in the Central Equatorial Pacific. J Clim 23:2869-2884. https://doi.org/10.1175/2010jcli3171.1

Yu YS,WS, Duan X, Hui, Mu M (2009) Dynamics of nonlinear error growth and season-dependent predictability of El Niño events in the Zebiak-Cane model. Quart J Roy Meteor Soc 135:2146-2160. https://doi.org/10.1002/qj.526

Zebiak SE, Cane MA (1987) A model El-Niño southern oscillation. Mon Weather Rev 115:2262-2278. https://doi.org/10.1175/15200493(1987)115<2262:Ameno>2.0.Co;2

Zhang RH, Gao C (2016a) The IOCAS intermediate coupled model (IOCAS ICM) and its real-time predictions of the 2015-2016 El Niño event. Sci Bull 61:1061-1070. https://doi.org/10.1007/s1143 4-016-1064-4

Zhang RH, Gao C (2016) Role of subsurface entrainment temperature (Te) in the onset of El Nino events, as represented in an intermediate coupled model. Clim Dyn 46(5):1417-1435. https://doi. org/10.1007/s00382-015-2655-5

Zhang RH, Gao C (2017) Processes involved in the second-year warming of the 2014-15 El Niño event as derived from an intermediate ocean model. Sci Chin Earth Sci 60(9):1601-1613. https://doi. org/10.1007/s11430-016-0201-

Zhang RH, Tao LJ, Gao C (2018) An improved simulation of the 2015 El Nio event by optimally correcting the initial conditions and model parameters in an intermediate coupled model. Clim Dynam 51:269-282. https://doi.org/10.1007/s00382-017-3919-z

Zhang RH, Zebiak SE, Kleeman R, Keenlyside N (2003) A new intermediate coupled model for El Niño simulation and prediction. Geophys Res Lett. https://doi.org/10.1029/2003GL018010

Zhang RH, Zebiak SE, Kleeman R, Keenlyside N (2005) Retrospective El Niño forecasts using an improved intermediate coupled model. Mon Weather Rev 133:2777-2802. https://doi.org/10.1175/ MWR3000.1

Zheng F, Zhu J (2016) Improved ensemble-mean forecasting of ENSO events by a zero-mean stochastic error model of an intermediate coupled model. Clim Dynam 47:3901-3915. https://doi. org/10.1007/s00382-016-3048-0

Zheng F, Yu JY (2017) Contrasting the skills and biases of deterministic predictions for the two types of El Niño. Adv Atmos Sci 34:1395-1403. https://doi.org/10.1007/s00376-017-6324-y

Publisher's Note Springer Nature remains neutral with regard to jurisdictional claims in published maps and institutional affiliations. 